\title{
The Clinical Significance of Procalcitonin Elevation in Patients over 75 Years Old Admitted for COVID-19 Pneumonia
}

\author{
Andrea Ticinesi $\left(\mathbb{D},{ }^{1}\right.$ Antonio Nouvenne ${ }^{D},{ }^{1}$ Beatrice Prati, ${ }^{1}$ Loredana Guida, ${ }^{1}$ \\ Alberto Parise ${ }^{1},{ }^{1}$ Nicoletta Cerundolo, ${ }^{1}$ Chiara Bonaguri ${ }^{(D)},{ }^{2}$ Rosalia Aloe, ${ }^{2}$ \\ Angela Guerra, ${ }^{1,3}$ and Tiziana Meschi $\mathbb{D}^{1,3}$ \\ ${ }^{1}$ Geriatric-Rehabilitation Department, Azienda Ospedaliero-Universitaria di Parma, Parma, Italy \\ ${ }^{2}$ Clinical Chemistry and Hematology Laboratory, Diagnostic Department, Azienda Ospedaliero-Universitaria di Parma, Parma, Italy \\ ${ }^{3}$ Department of Medicine and Surgery, University of Parma, Parma, Italy \\ Correspondence should be addressed to Andrea Ticinesi; aticinesi@ao.pr.it
}

Received 9 February 2021; Revised 28 May 2021; Accepted 16 June 2021; Published 30 June 2021

Academic Editor: Sandra Helena Penha Oliveira

Copyright ( 2021 Andrea Ticinesi et al. This is an open access article distributed under the Creative Commons Attribution License, which permits unrestricted use, distribution, and reproduction in any medium, provided the original work is properly cited.

\begin{abstract}
Aim. To investigate the clinical significance of procalcitonin (PCT) elevation on hospital admission for coronavirus disease-19 (COVID-19) and its association with mortality in oldest old patients (age $>75$ years). Methods. The clinical records of 1074 patients with chest high-resolution computed-tomography (HRCT) positive for interstitial pneumonia and symptoms compatible for COVID-19, hospitalized in medical wards during the first pandemic wave in a single academic center in Northern Italy, were retrospectively analyzed. All patients had serum PCT testing performed within six hours from admission. Information on COVID-19-related symptoms, comorbidities, drugs, autonomy in daily activities, respiratory exchanges, other routine lab tests, and outcomes were collected. Clinical characteristics were compared across different admission PCT levels and ages. The association of admission PCT with mortality was tested separately in participants aged $>75$ and $\leq 75$ years old by stepwise multivariate Cox regression model with forward selection. Results. With increasing classes of PCT levels $(<0.05$, 0.05$0.49,0.5-1.99$, and $\geq 2 \mathrm{ng} / \mathrm{ml})$, there was a significant trend $(P<0.0001)$ towards older age, male gender, wider extension of lung involvement on HRCT, worse respiratory exchanges, and several other laboratory abnormalities. Each incremental PCT class was associated with increased risk of hospital death at multivariate models in subjects older than 75 (hazard ratio for PCT $\geq 2$ vs. $<0.05 \mathrm{ng} / \mathrm{ml}$ : $30.629,95 \%$ confidence interval 4.176-224.645, $P=0.001$ ), but not in subjects aged 75 or younger. Conclusions. In patients admitted for COVID-19, PCT elevation was associated with several clinical, radiological, and laboratory characteristics of disease severity. However, PCT elevation was strongly associated with hospital mortality only in oldest old subjects (age $>75$ ).
\end{abstract}

\section{Introduction}

Serum procalcitonin (PCT) elevation is frequently seen in patients hospitalized for moderate or severe forms of coronavirus disease-19 (COVID-19) [1]. The main trigger for PCT synthesis is the presence of circulating endotoxins $[1,2]$. For this reason, in clinical practice, PCT is generally considered a biomarker of systemic bacterial infections and has been interpreted as an indicator of secondary bacterial infection in COVID-19 [2].

However, PCT synthesis can also be stimulated by the elevation of proinflammatory cytokines, including interleukin-6 (IL-6), interleukin-1b (IL-1b), and tumor necrosis factor- $\alpha$ (TNF- $\alpha$ ) [1]. These mediators are massively involved in the so-called cytokine storm, typical of the progression from the viremic to the hyperinflammatory stage of COVID-19 and characterized by the onset of respiratory symptoms and interstitial pulmonary infiltrates on chest radiology [3]. Thus, PCT elevation may represent a direct consequence of the COVID-19 cytokine storm and could also be interpreted in the framework of a "viral sepsis" syndrome [4].

Several systematic reviews and meta-analyses have indicated PCT elevation as a prognostic biomarker of adverse 
outcomes in COVID-19, including progression from moderate to severe and critical forms of the disease, intensive care unit (ICU) admission, need for mechanical ventilation, and mortality [5-15]. PCT shares this prognostic role with many other biomarkers of inflammation, including IL-6, C-reactive protein (CRP), D-dimer, and white blood cell (WBC) elevation [5-10].

However, most of the evidence linking PCT elevation on hospital admission for COVID-19 with adverse outcomes is based on small-sized studies with retrospective design, conducted on Chinese populations during the very early phases of the COVID-19 pandemic [6-10]. The demography of such populations is very different from that of Western patients admitted for COVID-19 that were generally older and with a higher burden of multimorbidity and frailty [16]. Data on the prognostic role of PCT elevation in these age groups are scarce.

In older subjects, inflammaging, immune senescence, and chronic inflammatory comorbidities can represent triggers to PCT synthesis even in the absence of infection, limiting the diagnostic and prognostic role of this biomarker [1719]. Studies conducted in geriatric patients with bacterial infection, however, suggest that PCT maintains a prognostic role in these age-groups, though with different cut-offs than in younger subjects [20-22].

The aim of this retrospective study was to investigate the association of PCT elevation on hospital admission for COVID-19 with mortality in patients older and younger than 75 years old, to clarify the prognostic significance of this biomarker in geriatric patients.

\section{Methods}

2.1. Study Setting and Population. The study was conducted at the Geriatric-Rehabilitation Department of Parma University-Hospital in Northern Italy during the first pandemic wave (Feb 28-Jun 10, 2020). This department was the main hub for the care of patients with COVID-19 not requiring intensive support of vital functions of an area of $>300,000$ inhabitants, including the urban area of Parma and several neighboring villages. The department has a capacity of 195 medical beds that were extended up to 330 in periods of extreme overflow of patients needing urgent care for COVID-19 [23].

Patients were admitted after an Emergency Department (ED) visit for typical symptoms of COVID-19 and after undergoing a high-resolution chest computed tomography (HRCT), with results compatible with the presence of interstitial pneumonia of viral origin [23]. Nasopharyngeal swab for the detection of Severe Acute Respiratory Syndrome CoronaVirus-2 (SARS-CoV-2) with Reverse-Transcriptase Polymerase-Chain Reaction (RT-PCR) was performed immediately after admission, as diagnostic confirmation [23]. These criteria of admission were based on the assumption that, during a pandemic wave, clinical and radiological findings typical of COVID-19 must be attributed to the disease with reasonable certainty even in the absence of an immediate molecular diagnostic confirmation. In fact, nasopharyngeal swabs frequently tested negative for SARS-CoV-
2 on hospital admission during the first pandemic wave, though patients were confirmed as having COVID-19 at a later stage [24].

The total number of patients admitted during the first pandemic wave (Feb 28-Jun 10, 2020) were 1684. Included in this study were 1074 patients with interstitial pneumonia confirmed on HRCT performed on the day of admission and with serum PCT levels tested within six hours from ward admission. We excluded all subjects under 18 years old, those lacking blood tests within six hours from ward admission, those with known conditions inducing severe immune suppression and those with indeterminate findings on chest HRCT.

The patients, who tested negative for SARS-CoV-2 on the day of admission, but exhibited typical radiologic signs of viral pneumonia, clinical presentation compatible with COVID-19, and a history of contact with confirmed COVID-19 cases were not excluded from the study, assuming false-negative molecular testing that was reported as very common in the early phases of the pandemic [25].

2.2. Data Collection and Outcome Measures. We retrospectively reviewed the clinical records of eligible patients, collecting demographic, clinical, and laboratory data. Namely, age, gender, duration, and type of symptoms before admission, number of chronic comorbidities, number of drugs, and dependency in daily activities were retrieved from each patient's history. Treatment with angiotensin-converting enzyme inhibitors (ACE-I) or angiotensin receptor blockers (ARBs) was particularly considered for its possible association with COVID-19 outcome. The characteristics of chest HRCT findings, including presence of consolidations and extension of ground-glass opacity abnormalities, determined using a visual scoring system described elsewhere [26], were also recorded from each clinical record. Abnormalities on the electrocardiogram (ECG) were also classified for each participant.

The results of RT-PCR testing on nasopharyngeal swabs for detection of SARS-CoV-2 performed within 12 hours from admission were collected.

Routine blood tests performed within 6 hours from ward admission included PCT, CRP, complete blood cell count, creatinine, urea, sodium, potassium, total bilirubin, aspartate aminotransferase (AST), creatine-phosphokinase (CPK), lactate dehydrogenase (LDH), fibrinogen, and D-dimer. Serum IL-6 levels were also determined in selected cases. The serum PCT levels were tested by a paramagnetic particle chemiluminescent immunoassay named Access PCT (Beckman Coulter, Brea, CA, USA).

Respiratory exchanges were evaluated in all participants on admission through the calculation of $\mathrm{PaO}_{2} / \mathrm{FiO}_{2}$ (arterial pressure of oxygen divided per the fractional oxygen flow administered).

The clinical course of COVID-19 was evaluated in this study through collection of the worst value of $\mathrm{PaO}_{2}$ at blood gas analysis and the highest oxygen flows administered.

In-hospital mortality was considered as the main outcome, while need for noninvasive ventilation (NIV) and ICU transferal were considered as secondary outcomes. 
TABLE 1: Overview of the main demographical, radiological, and virological characteristics on admission of the 1074 patients included in the study, stratified according to procalcitonin levels on admission.

\begin{tabular}{|c|c|c|c|c|c|c|}
\hline & $\begin{array}{c}\mathrm{PCT}<0.05 \mathrm{ng} / \mathrm{ml} \\
\quad(N=130)\end{array}$ & $\begin{array}{c}\text { PCT } \geq 0.05-<0.5 \mathrm{ng} / \mathrm{ml} \\
(N=698)\end{array}$ & $\begin{array}{c}\mathrm{PCT} \geq 0.5-<2 \mathrm{ng} / \mathrm{ml} \\
\quad(N=145)\end{array}$ & $\begin{array}{l}\mathrm{PCT} \geq 2 \mathrm{ng} / \mathrm{ml} \\
\quad(N=101)\end{array}$ & $P$ & $\begin{array}{l}P \text { for } \\
\text { trend }\end{array}$ \\
\hline Age, years & $65(58-80)$ & $74(63-83)$ & $78(68-84)$ & $78(70-85)$ & $<0.001$ & $<0.001$ \\
\hline Females, \% & 65 & 43 & 35 & 34 & $<0.001$ & $<0.001$ \\
\hline Consolidations on HRCT, \% & 56 & 70 & 65 & 73 & 0.009 & 0.069 \\
\hline HRCT visual score & $20(15-30)$ & $30(20-48)$ & $40(25-60)$ & $35(20-56)$ & $<0.001$ & $<0.001$ \\
\hline $\begin{array}{l}\text { First swab positive for } \\
\text { SARS-CoV- } 2, \%\end{array}$ & 55 & 65 & 69 & 69 & 0.082 & 0.032 \\
\hline
\end{tabular}

Data reported as median and interquartile range (IQR) or percentage. $P$ values calculated with Kruskal-Wallis or chi-square tests, $P$ for trend with ANOVA. $P$ values $<0.05$ are indicated in bold (PCT: procalcitonin; HRCT: high-resolution computed tomography; SARS-CoV-2: Severe Acute Respiratory Syndrome CoronaVirus-2).

2.3. Statistical Analysis. Variables were expressed as median and interquartile range (IQR) or as percentages, as appropriate. The normality of distribution of continuous variables was assessed with the Kolmogorov-Smirnov test. PCT levels on admission were considered as the independent variable. The population was divided into four groups, according to PCT levels: $<0.05 \mathrm{ng} / \mathrm{ml}$ (group 1, normal), $\geq 0.05 \mathrm{ng} / \mathrm{ml}$ and $<0.5 \mathrm{ng} / \mathrm{ml}$ (group 2, mild elevation), $\geq 0.5 \mathrm{ng} / \mathrm{ml}$ and $<2$ $\mathrm{ng} / \mathrm{ml}$ (group 3, severe elevation), and $\geq 2 \mathrm{ng} / \mathrm{ml}$ (group 4 , extreme elevation). These cut-offs were compatible with those used for prescription of antibiotic therapy in suspected bacterial infections [27]. All demographic, clinical, laboratory, and outcome data were compared across these four groups using Kruskal-Wallis test, linear regression, univariate general linear model, one-way analysis of variance (ANOVA) for continuous variables, and Pearson chi-square test and logistic regression for dichotomous variables. All demographic, radiological, and virological characteristics showing a significantly different trend across PCT classes were considered as potential confounders in regression models. In particular, age, sex, positive RT-PCR test for SARS-CoV-2, and presence of consolidations on chest HRCT were considered as possible confounders, for their established influence on COVID-19 clinical presentation and prognosis $[28,29]$.

Then, the association of different PCT classes upon admission with in-hospital mortality was evaluated separately for patients older than 75 and for patients aged 75 or younger with Cox regression multivariate analysis. Included as possible confounders were all demographic, radiological, and virological characteristics with significantly different trend across PCT classes (namely, age, sex, presence of consolidations on chest HRCT, and positive nasopharyngeal swab for SARS-CoV-2) and treatment with ACE-I or ARBs, for its possible association with COVID-19 outcome.

$P$ values were considered significant when $<0.05$. Statistical analyses were performed with the SPSS package (v.26, IBM, Armonk, United States).

2.4. Ethical Statement. The study was approved by the local Ethics Committee as part of a larger retrospective project on the clinical correlates of COVID-19 in hospitalized patients (ID 273/2020/OSS/AOUPR, Comitato Etico del-
l'Area Vasta Emilia Nord). Due to the retrospective design of the study, informed consent was obtained only whenever possible, in compliance with the current regulations.

\section{Results}

Among the 1074 patients included in the study, 524 were older than 75 years old, while 550 were aged 75 or younger. Only 130 patients had normal serum PCT values on admission $(<0.05 \mathrm{ng} / \mathrm{ml}$, group 1$)$, while the numbers of patients classified as having mild elevation (group 2), severe elevation (group 3), and extreme elevation (group 4) were 698, 145, and 101, respectively (Table 1 ). There was a significant trend of older age $(P<0.001)$, reduced representation of female gender $(P<0.001)$, wider extension of lung parenchyma abnormalities on chest HRCT $(P<0.001)$, and higher prevalence of nasopharyngeal swabs positive for SARS-CoV-2 $(P=0.032)$ with increasing classes of PCT level (Table 1$)$.

PCT elevation on admission was also positively associated with dependency in daily activities, number of comorbidities, number of drugs, and presence of obesity and chronic kidney disease (Table 2). The chronic use of medications acting on the renin-angiotensin-aldosterone system, such as angiotensin-converting enzyme inhibitors or angiotensin receptor blockers, was not different across PCT classes (Table 2). Patients with extreme PCT elevation had also a shorter duration of COVID-19-related symptoms before admission and higher prevalence of dyspnea and electrocardiogram abnormalities (Table 2).

A trend towards worse respiratory exchanges was also identified with increasing PCT levels $\left(\mathrm{PaO}_{2} / \mathrm{FiO}_{2}\right.$ group 1: $357 \mathrm{mmHg}$, IQR 290-406; group 2: $257 \mathrm{mmHg}$, IQR 173333; group 3: $141 \mathrm{mmHg}$, IQR 84-260; group 4: $171 \mathrm{mmHg}$, IQR 87-278; $P<0.001$ adjusted for age, sex, consolidations, and positive nasopharyngeal swab) (Table 3). PCT elevation was also associated with a higher prevalence of laboratory abnormalities on admission, namely, neutrophilia, lymphopenia, elevation of D-dimer, fibrinogen, AST, LDH, and CPK (Table 3 and Table 4). It was also associated with an increasing trend of elevation of other inflammatory markers, including CRP and IL-6 (Table 3).

As shown in Table 4, classes of PCT elevation on admission were associated with increased frequency of noninvasive 
TABLE 2: Anamnestic and electrocardiographic characteristics the 1074 study participants, stratified according to procalcitonin levels on admission.

\begin{tabular}{|c|c|c|c|c|c|c|}
\hline & $\begin{array}{c}\mathrm{PCT}<0.05 \mathrm{ng} / \mathrm{ml} \\
\quad(N=130)\end{array}$ & $\begin{array}{l}\mathrm{PCT} \geq 0.05-<0.5 \\
\mathrm{ng} / \mathrm{ml}(N=698)\end{array}$ & $\begin{array}{c}\mathrm{PCT} \geq 0.5-<2 \\
\mathrm{ng} / \mathrm{ml}(N=145)\end{array}$ & $\begin{array}{l}\mathrm{PCT} \geq 2 \mathrm{ng} / \mathrm{ml} \\
\quad(N=101)\end{array}$ & $P^{*}$ & $\begin{array}{c}P<0.05 \\
\text { Standardized } \beta \text { or odds ratio }\end{array}$ \\
\hline \multicolumn{7}{|l|}{ Personal history } \\
\hline $\begin{array}{l}\text { Total dependency in } \\
\text { daily activities, \% }\end{array}$ & 9 & 18 & 15 & 30 & 0.017 & $1.33(1.05-1.68)$ \\
\hline $\begin{array}{l}\text { Chronic diseases, } \\
\text { number }\end{array}$ & $2(1-4)$ & $3(1-4)$ & $3(2-4)$ & $4(2-5)$ & 0.028 & 0.062 \\
\hline Drugs, number & $3(0-6)$ & $3(1-6)$ & $4(2-7)$ & $5(3-8)$ & 0.002 & 0.092 \\
\hline Hypertension, \% & 47 & 58 & 65 & 66 & 0.080 & \\
\hline Diabetes, \% & 14 & 19 & 24 & 27 & 0.225 & \\
\hline Obesity, \% & 8 & 12 & 16 & 12 & 0.031 & $1.31(1.03-1.68)$ \\
\hline $\begin{array}{l}\text { Chronic heart disease, } \\
\%\end{array}$ & 22 & 22 & 33 & 35 & 0.166 & \\
\hline $\begin{array}{l}\text { Chronic kidney } \\
\text { disease, } \%\end{array}$ & 2 & 5 & 10 & 20 & $<0.001$ & $1.97(1.48-2.62)$ \\
\hline ACE-I treatment, \% & 16 & 24 & 26 & 22 & 0.946 & \\
\hline $\mathrm{ARB}$ treatment, $\%$ & 20 & 16 & 18 & 23 & 0.723 & \\
\hline \multicolumn{7}{|l|}{$\begin{array}{l}\text { COVID-19-related } \\
\text { symptoms }\end{array}$} \\
\hline $\begin{array}{l}\text { Duration of symptoms, } \\
\text { days }\end{array}$ & $7(4-10)$ & $7(4-10)$ & $7(4-10)$ & $5(3-7)$ & 0.034 & -0.069 \\
\hline Cough, \% & 50 & 48 & 47 & 32 & 0.065 & \\
\hline Dyspnea, \% & 45 & 52 & 61 & 64 & 0.009 & $1.26(1.06-1.49)$ \\
\hline Diarrhea, \% & 9 & 7 & 8 & 9 & 0.360 & \\
\hline Fever, \% & 75 & 84 & 80 & 85 & 0.124 & \\
\hline \multicolumn{7}{|l|}{$\begin{array}{l}\text { Electrocardiogram } \\
\text { abnormalities on } \\
\text { admission }\end{array}$} \\
\hline $\begin{array}{l}\text { Electrocardiogram } \\
\text { abnormalities, \% }\end{array}$ & 38 & 47 & 59 & 69 & $<0.001$ & $1.44(1.20-1.72)$ \\
\hline $\begin{array}{r}\text { Repolarization } \\
\text { abnormalities, \% }\end{array}$ & 22 & 26 & 31 & 42 & 0.001 & $1.35(1.12-1.62)$ \\
\hline Atrial fibrillation, \% & 5 & 10 & 15 & 19 & 0.008 & $1.42(1.10-1.84)$ \\
\hline$\%$ Other tachiarrythmias, & 2 & 4 & 6 & 13 & 0.007 & $1.59(1.14-2.21)$ \\
\hline QTC, msec & $442(420-461)$ & $445(427-467)$ & $449(437-480)$ & $459(436-487)$ & 0.019 & 0.085 \\
\hline
\end{tabular}

${ }^{*} P$ adjusted for age, sex, consolidations, and positive nasopharyngeal swab. Data shown as median and interquartile range (IQR) or percentage. $P$ values calculated with linear regression for continuous variables and logistic regression for dichotomous variables (PCT: procalcitonin; COVID-19: CoronaVirus Disease-19; ACE-I: angiotensin-converting enzyme inhibitors; ARB: angiotensin receptor blocker; QTC: QT interval corrected according to the Bazin formula).

ventilation, ICU admission, and hospital mortality. Higher rates of mortality with increasing admission PCT classes were observed in both patients aged $\leq 75$ (group 1: $3 \%$; group 2: $10 \%$; group 3: $17 \%$; group 4: $25 \%$ ) and in patients older than 75 (group 1: 5\%; group 2: $33 \%$; group 3: 55\%; group 4: $68 \%$ ), but mortality was significantly higher for each PCT class in subjects older than 75 (Table 4).

In multivariate Cox regression analysis models, admission PCT classes discriminated the risk of mortality $(P<0.001)$ only in patients older than 75 years old (Table 5, model 2; Figure 1(b)) and not in patients aged 75 or younger (Table 5, model 1; Figure 1(a)), where age was instead the main factor associated with hospital mortality (HR 1.134, 95\% CI 1.082-1.189, $P<0.001$ ).

\section{Discussion}

In a large group of patients admitted with clinical and radiological findings compatible with COVID-19 pneumonia during the first pandemic wave in an academic hospital in Northern Italy, admission levels of serum PCT were associated with more severe characteristics of disease. However, PCT was significantly associated with the risk of adverse outcomes only in subjects older than 75 years old. In patients aged 75 and younger, instead, PCT was not so good in discriminating the risk of mortality, especially for levels $<2$ $\mathrm{ng} / \mathrm{ml}$.

These results confirm the role of PCT as a possible biomarker of severe COVID-19 and predictor of adverse 
TABLE 3: Laboratory tests on admission of the 1074 study participants, stratified according to procalcitonin levels.

\begin{tabular}{|c|c|c|c|c|c|c|}
\hline & $\begin{array}{c}\mathrm{PCT}<0.05 \mathrm{ng} / \mathrm{ml} \\
\quad(N=130)(1)\end{array}$ & $\begin{array}{c}\mathrm{PCT} \geq 0.05-<0.5 \\
\mathrm{ng} / \mathrm{ml}(N=698) \\
(2)\end{array}$ & $\begin{array}{c}\mathrm{PCT} \geq 0.5-<2 \\
\mathrm{ng} / \mathrm{ml}(N=145) \\
(3)\end{array}$ & $\begin{array}{l}\mathrm{PCT} \geq 2 \mathrm{ng} / \mathrm{ml} \\
(N=101)(4)\end{array}$ & $P^{*}$ & $\begin{array}{c}P<0.05 \\
\text { Bonferroni test }\end{array}$ \\
\hline \multicolumn{7}{|l|}{ Blood gas analysis } \\
\hline $\mathrm{pH}$ & $7.44(7.41-7.46)$ & $7.45(7.43-7.48)$ & $7.44(7.41-7.47)$ & $\begin{array}{c}7.42(7.38- \\
7.47)\end{array}$ & $<0.001$ & (4) vs. (2) \\
\hline Bicarbonate, $\mathrm{mmol} / \mathrm{l}$ & $25(24-27)$ & $25(23-27)$ & $25(22-28)$ & $22(20-25)$ & $<0.001$ & (4) vs. (1) vs. (2) vs. (3) \\
\hline $\mathrm{PaCO}_{2}, \mathrm{mmHg}$ & $37(35-41)$ & $36(33-39)$ & $36(32-40)$ & $34(30-38)$ & 0.005 & (4) vs. (1) vs. (2) \\
\hline $\mathrm{PaO}_{2} / \mathrm{FiO}_{2}, \mathrm{mmHg}$ & $357(290-406)$ & $257(173-333)$ & $141(84-260)$ & $171(87-278)$ & $<0.001$ & $\begin{array}{l}\text { (1) vs. (2) vs. (3) vs. (4) } \\
\text { (2) vs. (3) }\end{array}$ \\
\hline \multicolumn{7}{|l|}{ Blood cell count } \\
\hline Hemoglobin, g/dl & $13.2(12.2-14.2)$ & $13.5(12.2-14.6)$ & $13.5(11.8-14.6)$ & $\begin{array}{l}13.1(10.6- \\
14.4)\end{array}$ & 0.001 & (4) vs. (1) vs. (2) vs. (3) \\
\hline Platelets, $1000 / \mathrm{mm}^{3}$ & $219(180-270)$ & $209(163-273)$ & $209(168-271)$ & $197(145-253)$ & 0.157 & \\
\hline Neutrophils, $\mathrm{n} / \mathrm{mm}^{3}$ & 3657 (2404-5189) & $4981(3540-7014)$ & $\begin{array}{c}7217(4833- \\
9829)\end{array}$ & $\begin{array}{c}9007(4726- \\
12398)\end{array}$ & $<0.001$ & $\begin{array}{l}\text { (1) vs. (2) vs. ( } 3 \text { ) vs. (4) } \\
\text { (2) vs. (3) vs. (4) }\end{array}$ \\
\hline Lymphocytes, $\mathrm{n} / \mathrm{mm}^{3}$ & $1154(856-1650)$ & $914(649-1247)$ & $894(560-1245)$ & $630(398-898)$ & $<0.001$ & $\begin{array}{l}\text { (1) vs. (2) vs. (3) vs. (4) } \\
(2) \text { and ( } 3 \text { ) vs. (4) }\end{array}$ \\
\hline \multicolumn{7}{|l|}{$\begin{array}{l}\text { Clinical chemistry and } \\
\text { inflammatory indexes }\end{array}$} \\
\hline Creatinine, $\mathrm{mg} / \mathrm{dl}$ & $0.7(0.6-0.9)$ & $0.9(0.7-1.1)$ & $1.0(0.9-1.6)$ & $1.5(0.9-2.7)$ & $<0.001$ & $\begin{array}{c}\text { (1) and (2) vs. (3) vs. (4); } \\
\text { (3) vs. (4) }\end{array}$ \\
\hline Urea, mg/dl & $32(24-41)$ & $43(31-59)$ & $65(41-98)$ & $78(55-127)$ & $<0.001$ & $\begin{array}{l}\text { (1) vs. (2) vs. (3) vs. (4); (2) } \\
\text { vs. (3) vs. (4); (3) vs. (4) }\end{array}$ \\
\hline Sodium, mEq/l & $139(137-140)$ & $138(135-140)$ & $137(135-140)$ & $137(134-140)$ & 0.429 & \\
\hline Potassium, mEq/l & $3.9(3.6-4.2)$ & $4.0(3.7-4.3)$ & $4.1(3.8-4.5)$ & $4.0(3.7-4.6)$ & 0.014 & (2) vs. (4) \\
\hline $\begin{array}{l}\text { Total bilirubine, } \\
\text { mg/dl }\end{array}$ & $0.6(0.5-0.7)$ & $0.7(0.5-0.9)$ & $0.8(0.6-1.0)$ & $0.7(0.5-0.9)$ & 0.023 & (1) vs. (3) \\
\hline AST, IU/l & $32(25-38)$ & $43(31-65)$ & $65(42-95)$ & $55(32-99)$ & $<0.001$ & (1) vs. (3) vs. (4); (2) vs. (3) \\
\hline $\mathrm{LDH}, \mathrm{IU} / \mathrm{l}$ & $257(209-305)$ & $340(269-432)$ & $440(350-612)$ & $399(283-624)$ & $<0.001$ & $\begin{array}{l}\text { (1) vs. (2) vs. (3) vs. (4) } \\
\text { (2) vs. (3) vs. (4) }\end{array}$ \\
\hline CPK, IU/l & $86(54-155)$ & $125(65-251)$ & $207(104-551)$ & $235(113-802)$ & $<0.001$ & (1) and (2) vs. (3) vs. (4) \\
\hline Fibrinogen, ng/dl & $502(394-592)$ & $596(502-730)$ & $708(552-806)$ & $648(535-806)$ & $<0.001$ & $\begin{array}{l}\text { (1) vs. (2) vs. (3) vs. (4) } \\
\text { (2) vs. (3) }\end{array}$ \\
\hline $\mathrm{CRP}, \mathrm{mg} / \mathrm{l}$ & $25(5-55)$ & $92(50-143)$ & $167(111-230)$ & $172(111-250)$ & $<0.001$ & $\begin{array}{l}\text { (1) vs. (2) vs. (3) vs. (4) } \\
\text { (2) vs. (3) vs. (4) }\end{array}$ \\
\hline IL-6, pg/ml & $31(19-84)$ & $126(61-246)$ & $173(100-272)$ & $236(124-731)$ & $<0.001$ & (4) vs. (1) vs. (2) vs. (3) \\
\hline D-dimer, ng/dl & $658(464-1068)$ & $990(626-1740)$ & $1374(862-2392)$ & $\begin{array}{c}1514(954- \\
2679)\end{array}$ & $<0.001$ & (3) vs. (1) vs. (2) \\
\hline
\end{tabular}

${ }^{*} P$ calculated with univariate general linear model (GLM) and adjusted for age, sex, consolidations, and positive nasopharyngeal swab.

Data shown as median and interquartile range (IQR) (PCT: procalcitonin; $\mathrm{PaCO}_{2}$ : arterial pressure of carbon dioxide; $\mathrm{PaO}_{2}$ : arterial pressure of oxygen; FiO ${ }_{2}$ : fraction of inspired oxygen; AST: aspartate aminotransferase; CPK: creatine phosphokinase; LDH: lactate dehydrogenase; CRP: C-reactive protein; IL-6: interleukin-6).

outcomes. However, in comparison with previous research, they contribute to clarify in which patient category PCT testing is associated with more prognostic information. In fact, PCT testing on admission for COVID-19 may be of particular importance in geriatric patients, where this biomarker is not only an indicator of severe disease but also a prognostic biomarker.

The diagnostic and prognostic value of PCT elevation in geriatric patients on hospital admission has been investigated by several studies in the pre-COVID-19 era, with conflicting results [17-22, 30-34]. Some of these studies have concluded that PCT elevation in older patients is significantly associated with bacterial pneumonia, sepsis, severity of infection, and mortality [20-22, 30, 31]. Other studies, instead, underlined that the diagnostic and prognostic performance of PCT elevation in these patients is nonsuperior and in some cases deliberately inferior, to that of serum CRP [19, 32-34], which is generally considered as the inflammatory biomarker guiding therapeutic choices in acute geriatric patients $[35,36]$. Therefore, PCT elevation was basically regarded as a marker of inflammation or infection in older patients and not as a reliable diagnostic or prognostic indicator [34]. 
TABLE 4: Prevalence of the main laboratory abnormalities and outcomes of the 1074 study participants, stratified according to procalcitonin levels.

\begin{tabular}{|c|c|c|c|c|c|c|}
\hline & $\begin{array}{c}\mathrm{PCT}<0.05 \mathrm{ng} / \mathrm{ml} \\
\quad(N=130)\end{array}$ & $\begin{array}{l}\mathrm{PCT} \geq 0.05-<0.5 \\
\mathrm{ng} / \mathrm{ml}(N=698)\end{array}$ & $\begin{array}{c}\mathrm{PCT} \geq 0.5-<2 \mathrm{ng} / \mathrm{ml} \\
\quad(N=145)\end{array}$ & $\begin{array}{l}\mathrm{PCT} \geq 2 \mathrm{ng} / \mathrm{ml} \\
\quad(N=101)\end{array}$ & $P^{*}$ & $\begin{array}{c}P<0.05 \text { OR } \\
(95 \% \mathrm{CI})\end{array}$ \\
\hline \multicolumn{7}{|l|}{$\begin{array}{l}\text { Prevalence of laboratory } \\
\text { abnormalities }\end{array}$} \\
\hline $\begin{array}{l}\text { Neutrophil count }>8000 / \mathrm{m} \\
\mathrm{m}^{3}, \%\end{array}$ & 7 & 18 & 41 & 57 & $<0.001$ & $\begin{array}{l}2.65(2.17- \\
\quad 3.24)\end{array}$ \\
\hline $\begin{array}{l}\text { Lymphocyte count }<1000 / \mathrm{m} \\
\mathrm{m}^{3}, \%\end{array}$ & 40 & 57 & 57 & 81 & $<0.001$ & $\begin{array}{l}1.48(1.24- \\
1.77)\end{array}$ \\
\hline Monocyte count $<200 / \mathrm{mm}^{3}$, & 6 & 10 & 17 & 25 & $<0.001$ & $\begin{array}{l}1.44(1.42- \\
2.28)\end{array}$ \\
\hline AST > $40 \mathrm{IU} / 1, \%$ & 31 & 51 & 69 & 63 & $<0.001$ & $\begin{array}{l}1.71(1.42- \\
2.07)\end{array}$ \\
\hline $\mathrm{LDH}>247 \mathrm{IU} / 1, \%$ & 58 & 84 & 90 & 84 & $<0.001$ & $\begin{array}{l}1.69(1.31- \\
2.19)\end{array}$ \\
\hline $\mathrm{CPK}>200 \mathrm{IU} / \mathrm{l}, \%$ & 25 & 38 & 62 & 63 & $<0.001$ & $\begin{array}{l}1.80(1.50- \\
2.16)\end{array}$ \\
\hline $\mathrm{D}-$ dimer $>500 \mathrm{ng} / \mathrm{dl}, \%$ & 69 & 87 & 94 & 94 & $<0.001$ & $\begin{array}{l}1.92(1.38- \\
2.67)\end{array}$ \\
\hline Fibrinogen > 400 ng/dl, \% & 73 & 89 & 91 & 88 & 0.028 & $\begin{array}{c}1.38(1.04- \\
1.84)\end{array}$ \\
\hline \multicolumn{7}{|l|}{ Outcomes } \\
\hline Noninvasive ventilation, $\%$ & 4 & 10 & 17 & 10 & 0.001 & $\begin{array}{l}1.55(1.20- \\
2.00)\end{array}$ \\
\hline ICU admission, \% & 1 & 4 & 9 & 3 & 0.011 & $\begin{array}{l}1.65(1.12- \\
2.41)\end{array}$ \\
\hline Death, \% & 4 & 21 & 39 & 52 & & \\
\hline $\begin{array}{l}\text { Death } \\
\text { (patients } \leq 75 \text { years old), \% }\end{array}$ & 3 & 10 & 17 & 25 & & \\
\hline $\begin{array}{l}\text { Death } \\
\text { (patients }>75 \text { years old), \% }\end{array}$ & 5 & 33 & 55 & 68 & & \\
\hline
\end{tabular}

${ }^{*} P$ calculated with logistic regression and adjusted for age, sex, consolidations, and positive nasopharyngeal swab. Data expressed as percentages (PCT: procalcitonin; OR: odds ratio; CI: confidence interval; AST: aspartate aminotransferase; LDH: lactate dehydrogenase; CPK: creatine phosphokinase; ICU: intensive care unit)

In comparison with other pulmonary infections, severe COVID-19 is characterized by massive activation of the inflammatory response, which is substantiated in the socalled "cytokine storm" with elevation of IL- 6 and TNF- $\alpha$ in blood. PCT elevation could represent a consequence of this pathological phenomenon characterizing the transition between the viremic and the organ damage phases of COVID-19, although it could also indicate some degree of bacterial superinfection on pulmonary interstitial lesions [3, 37].

In older patients, preexisting frailty and multimorbidity could be associated with chronic activation of the inflammatory system, the so-called inflammaging [38, 39]. We can hypothesize that this condition exacerbates the reactivity of the inflammatory and immune system to SARSCoV-2 infection, promoting the cytokine storm and resulting in increased levels of inflammatory biomarkers, including PCT, in comparison with adult subjects. Recent studies have in fact suggested that the presence of frailty and multimorbidity could represent risk factors for adverse outcomes of COVID-19 beyond chronological age [40-42], although the severity of clinical presentation of respiratory failure remains the strongest prognostic indicator in all patients [42, 43]. The pronounced association between PCT elevation and hospital mortality, observed in participants over 75 years old, could thus represent the effect of increased burden of frailty and multimorbidity in such patients.

These conditions could also drive an increased risk of pulmonary bacterial superinfection in patients hospitalized for COVID-19. In this case, the association between PCT elevation and mortality could simply represent an indicator of this complication of COVID-19. However, bacterial superinfections are difficult to detect in COVID-19 patients, especially in a context of massive hospital overcrowding as the one in which our investigation was conducted. The few studies that were specifically focused on this issue gave conflicting results $[44,45]$. For example, Falcone and colleagues found a substantial prevalence of bacterial and fungal superinfections $(21.9 \%)$ in a group of 315 patients hospitalized for COVID19 in Italy [44], while Garcia-Vidal and colleagues showed that bacterial superinfections were uncommon (prevalence $3.1 \%$ ) in their cohort of 989 hospitalized patients [45]. Thus, 
TABLE 5: Multivariate Cox regression model, testing variables associated with hospital mortality.

\begin{tabular}{|c|c|c|c|}
\hline & Hazard ratio & 95\% confidence interval & $P^{\mathrm{a}}$ \\
\hline \multicolumn{4}{|c|}{ Model 1 -patients aged 75 or younger $(n=550)$} \\
\hline Age, years & 1.134 & $1.082-1.189$ & $<0.001$ \\
\hline Sex, female vs. male & 0.993 & $0.558-1.768$ & 0.981 \\
\hline ACE-I treatment & 0.706 & $0.376-1.327$ & 0.279 \\
\hline ARB treatment & 1.144 & $0.588-2.225$ & 0.692 \\
\hline Consolidations on chest HRCT & 1.312 & $0.718-2.396$ & 0.377 \\
\hline Nasopharyngeal swab positive for SARS-CoV-2 & 1.680 & $0.863-3.271$ & 0.127 \\
\hline Procalcitonin* & & & 0.060 \\
\hline Level 2 vs. level 1 & 1.185 & $0.357-3.930$ & 0.782 \\
\hline Level 3 vs. level 1 & 1.600 & $0.429-5.974$ & 0.484 \\
\hline Level 4 vs. level 1 & 3.308 & $0.855-12.804$ & 0.083 \\
\hline \multicolumn{4}{|c|}{ Model 2 -patients aged $>75$ years old $(n=524)$} \\
\hline Age, years & 1.013 & $0.986-1.041$ & 0.348 \\
\hline Sex, female vs. male & 0.916 & $0.677-1.239$ & 0.568 \\
\hline ACE-I treatment & 1.016 & $0.714-1.446$ & 0.929 \\
\hline ARB treatment & 0.804 & $0.529-1.221$ & 0.306 \\
\hline Consolidations on chest HRCT & 1.130 & $0.817-1.564$ & 0.459 \\
\hline Nasopharyngeal swab positive for SARS-CoV-2 & 1.816 & $1.268-2.602$ & 0.001 \\
\hline Procalcitonin* & & & $<0.001$ \\
\hline Level 2 vs. level 1 & 13.388 & $1.861-96.301$ & 0.010 \\
\hline Level 3 vs. level 1 & 31.090 & $4.240-227.985$ & 0.001 \\
\hline Level 4 vs. level 1 & 30.629 & $4.176-224.645$ & 0.001 \\
\hline
\end{tabular}

${ }^{*}$ Procalcitonin level 1: $<0.05 \mathrm{ng} / \mathrm{ml}$; level $2: \geq 0.05$ and $<0.5 \mathrm{ng} / \mathrm{ml}$; level $3: \geq 0.5$ and $<2 \mathrm{ng} / \mathrm{ml}$; level 4: $\geq 2 \mathrm{ng} / \mathrm{ml}$. ACE-I: angiotensin-converting enzyme inhibitors; ARB: angiotensin receptor blockers; HRCT: high-resolution computed tomography.

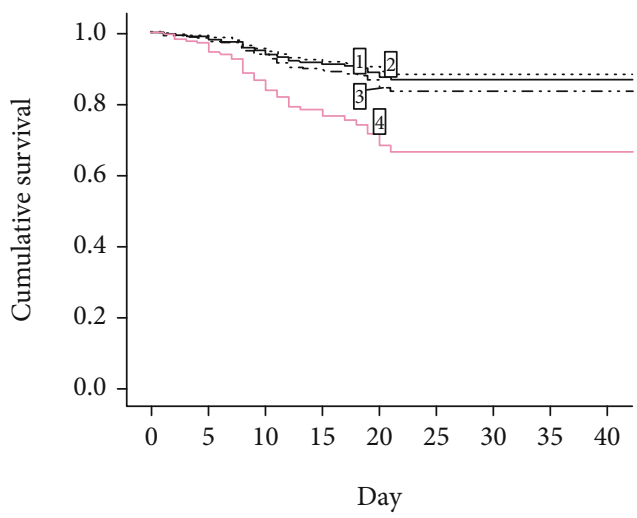

(a)

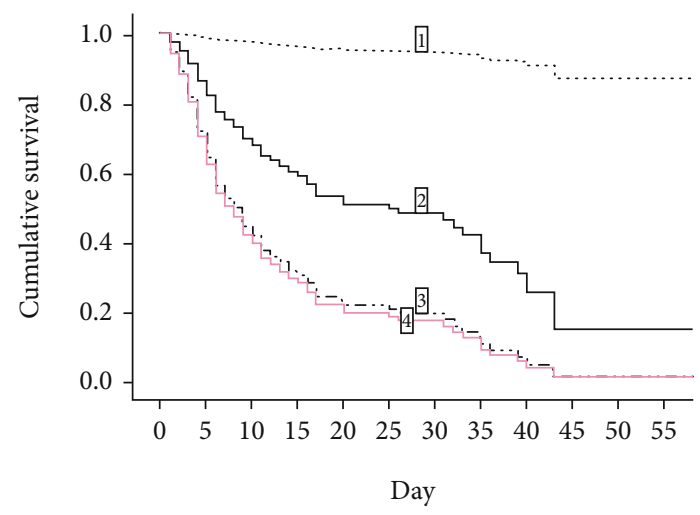

(b)

FIGURE 1: Survival functions, determined by Cox regression analysis, of participants stratified according to levels of procalcitonin on admission (level 1: $<0.05 \mathrm{ng} / \mathrm{ml}$; level 2: $\geq 0.05$ and $<0.5 \mathrm{ng} / \mathrm{ml}$; level 3: $\geq 0.5$ and $<2 \mathrm{ng} / \mathrm{ml}$; level $4: \geq 2 \mathrm{ng} / \mathrm{ml}$ ) and age ((a) age $\leq 75 \mathrm{years}$ old; (b) age $>75$ years old).

the current evidence does not allow to attribute PCT elevation exclusively to bacterial superinfection in patients hospitalized for COVID-19.

In our study, the presence of bacterial superinfection was not systematically assessed, due to the emergency situation and overcrowding of hospital wards. Blood and sputum cultures could be obtained only in a minority of cases and were negative for the presence of pathogens. However, the circum- stance that the trend of prevalence of pulmonary consolidations on chest CT, a possible sign of bacterial superinfection in interstitial pneumonia, was not significant with increasing PCT classes (Table 1) suggests that other mechanisms could be involved in PCT elevation.

Most studies that investigated the association between PCT elevation and prognosis of COVID-19 in hospitalized patients were mainly conducted in adult subjects and 
included only a very small number of seniors over 75 years old [6-10]. On the other side, the main studies that have investigated the clinical presentation and prognostic factors of COVID-19 in older individuals did not include data on PCT testing on admission [40, 41].

The only exception was the study by Chen and colleagues, who detected significantly lower serum PCT values on admission for COVID-19 in subjects older than 65 in comparison with adult subjects [46]. However, this study included just a small number of geriatric patients (only 55 participants older than 65) and was conducted in China during the very first phases of the COVID-19 pandemic [46]. Thus, the setting was substantially different from that of the present investigation, which was conducted on a much larger sample with a substantial proportion of older individuals.

The associations between PCT levels on admission and other different clinical, radiological, and laboratory parameters of COVID-19 confirmed that PCT elevation represents a marker of disease severity at all ages. However, in subjects aged 75 or younger, this association did not translate into substantial adverse outcome prediction. From the epidemiological point of view, this circumstance suggests that other factors, different from inflammatory parameters, may substantially influence the mortality risk in adult patients. Such factors could include chronic comorbidities, SARS-CoV-2 viral load, host genotyperelated factors, and chronological age $[12,47,48]$, but not chronic medications. Drugs like ACE-I and ARBs, that were associated with COVID-19 outcomes in previous studies from China [49], were not associated with mortality in our population, matching the findings of a nationwide study conducted in our country [50].

The association between PCT and mortality detected in geriatric patients suggests that younger subjects may be more resilient to the hyperinflammatory state associated with the second phase of COVID-19 than older patients, reflecting a reduced prevalence of frailty and chronic illness [16]. Chronological age could also represent an important prognostic factor only in younger subjects because of a ceiling effect in the relationship between severe COVID-19 and mortality in subjects older than 75. In fact, mortality was low under the age of 65 and peaked after the age of 75 . Every small increment of age in the range 65-75 was probably associated with a substantial increase in the risk of death, while every small increment of age after 75 years old was not associated with further increases in the risk of death because mortality was already maximal in this age range.

Some limitations should be considered when interpreting the findings of our study. First, the retrospective design prevents to draw any robust causal inference on the role of PCT as predictor of adverse outcomes in COVID-19, but simply suggests an association requiring further confirmation in future studies with prospective design. The inclusion of patients who tested negative for SARS-CoV-2 on the day of admission, despite anamnestic, clinical, and radiological findings compatible with COVID19 , should be also considered as a potential source of bias, since the diagnosis was not confirmed in conformity with international standards. However, false-negative nasopharyngeal tests for SARS-CoV-2 were frequently reported during the early phases of the pandemic [25]. Individual susceptibility factors to severe clinical course, including genetic polymorphisms that have a known relationship with COVID-19-related mortality [51, 52], were not investigated.

Moreover, the particular circumstances of massive hospital overcrowding during the first month of the pandemic outbreak should be considered as another issue limiting the validity and generalizability of results. The relatively low rate of ICU admission should thus be interpreted in the context of an emergency situation with resource constraints. Information on long-term outcomes of survivors, after hospital discharge, were also unavailable. Such information could have been useful to verify whether hyperinflammatory state with PCT elevation on admission was associated with COVID19 sequelae or late mortality. Finally, a thorough assessment of the possible presence of bacterial superinfections was not possible in a large number of patients.

Such limitations are however counterbalanced by remarkable points of strength. This is one of the few studies specifically focused on PCT elevation in oldest old patients. The large sample size of COVID-19 patients of different ages allowed us to verify the clinical significance of PCT elevation in both adult and geriatric patients, especially in relation to the burden of frailty and multimorbidity.

\section{Conclusions}

In a large group of patients hospitalized for suspect COVID-19 during the first pandemic wave in Italy, PCT elevation on admission was associated with other clinical, laboratory, and radiological parameters of disease severity. However, PCT elevation was significantly associated with hospital mortality risk only in subjects older than 75, suggesting that PCT may represent an excellent prognostic biomarker of COVID-19 especially in geriatric patients.

\section{Data Availability}

Data are available from the authors, in rigorously anonymous form, upon reasonable request.

\section{Conflicts of Interest}

The authors declare no conflict of interest regarding the publication of this paper.

\section{Acknowledgments}

The authors wish to thank Dr Ilaria Zanichelli for assistance in protocol writing and Dr. Dario Magnani, Dr. Laura Frosio, and Dr. Martina Roccoberton for assistance in data collection. The authors are also grateful to Mr. Bruno Rastelli for his support in research activities on COVID-19. 


\section{References}

[1] G. Ponti, M. Maccaferri, C. Ruini, A. Tomasi, and T. Ozben, "Biomarkers associated with COVID-19 disease progression," Critical Reviews in Clinical Laboratory Sciences, vol. 57, no. 6, pp. 389-399, 2020.

[2] N. Vazzana, F. Dipaola, and S. Ognibene, "Procalcitonin and secondary bacterial infections in COVID-19: association with disease severity and outcomes," Acta Clinica Belgica, pp. 1-5, 2020.

[3] D. C. Fajgenbaum and C. H. June, "Cytokine storm," New England Journal of Medicine, vol. 383, no. 23, pp. 2255-2273, 2020.

[4] H. Li, L. Liu, D. Zhang et al., "SARS-CoV-2 and viral sepsis: observations and hypotheses," Lancet, vol. 395, no. 10235, pp. 1517-1520, 2020.

[5] Y. Tjendra, A. F. al Mana, A. P. Espejo et al., "Predicting disease severity and outcome in COVID-19 patients: a review of multiple biomarkers," Archives of Pathology and Laboratory Medicine, vol. 144, no. 12, pp. 1465-1474, 2020.

[6] R. M. Elshazli, E. A. Toraih, A. Elgami et al., "Diagnostic and prognostic value of hematological and immunological markers in COVID-19 infection: a meta-analysis of 6320 patients," PLoS One, vol. 15, no. 8, article 0238160, 2020.

[7] I. Huang, R. Pranata, M. A. Lim, A. Oehadian, and B. Alisjahbana, "C-reactive protein, procalcitonin, D-dimer, and ferritin in severe coronavirus disease-2019: a meta-analysis," Therapeutic Advances in Respiratory Diseases, vol. 14, pp. 1-14, 2020.

[8] X. Feng, S. Li, Q. Sun et al., "Immune-inflammatory parameters in COVID-19 cases: a systematic review and meta-analysis," Frontiers in Medicine, vol. 7, no. 7, p. 301, 2020.

[9] H. Akbari, R. Tabrizi, K. B. Lankarani et al., "The role of cytokine profile and lymphocyte subsets in the severity of coronavirus disease 2019 (COVID-19): a systematic review and metaanalysis," Life Sciences, vol. 258, article 118167, 2020.

[10] P. Malik, U. Patel, D. Mehta et al., "Biomarkers and outcomes of COVID-19 hospitalisations: systematic review and metaanalysis," British Medical Journal Evidence-Based Medicine, vol. 26, no. 3, pp. 107-108, 2021.

[11] G. Lippi and M. Plebani, "Procalcitonin in patients with severe coronavirus disease 2019 (COVID-19): a meta-analysis," Clinica Chimica Acta, vol. 505, pp. 190-191, 2020.

[12] S. Figliozzi, P. G. Masci, N. Ahmadi et al., "Predictors of adverse prognosis in COVID-19: a systematic review and meta-analysis," European Journal of Clinical Investigation, vol. 50, article e13362, 2020.

[13] Z. Zheng, F. Peng, B. Xu et al., "Risk factors of critical \& mortal COVID-19 cases: a systematic literature review and metaanalysis," Journal of Infection, vol. 81, no. 2, pp. e16-e25, 2020.

[14] A. Izcovich, M. A. Ragusa, F. Tortosa et al., "Prognostic factors for severity and mortality in patients infected with COVID-19: a systematic review," PLoS One, vol. 15, no. 11, article e0241955, 2020.

[15] L. Xu, Y. Mao, and G. Chen, "Risk factors for 2019 novel coronavirus disease (COVID-19) patients progressing to critical illness: a systematic review and meta-analysis," Aging, vol. 12, no. 12, pp. 12410-12421, 2020.

[16] L. Palmieri, N. Vanacore, C. Donfrancesco et al., "Clinical characteristics of hospitalized individuals dying with COVID-19 by age group in Italy," The Journals of Gerontology
Series A Biological Sciences Medical Sciences, vol. 75, no. 9, pp. 1796-1800, 2020.

[17] Y. Yang, Q. Hao, J. H. Flaherty et al., "Comparison of procalcitonin, a potentially new inflammatory biomarker of frailty, to interleukin-6 and C-reactive protein among older Chinese hospitalized patients," Aging Clinical and Experimental Research, vol. 30, pp. 1459-1464, 2020.

[18] D. Viasus, A. F. Simonetti, A. F. Estupiñan-Bohórquez, and J. Carratalà, "Effect of age and comorbidities on serum levels of inflammatory markers in community-acquired pneumonia," European Journal of Clinical Investigation, vol. 51, no. 6, article e13480, 2021.

[19] A. Nouvenne, A. Ticinesi, G. Folesani et al., "The association of serum procalcitonin and high-sensitivity C-reactive protein with pneumonia in elderly multimorbid patients with respiratory symptoms: retrospective cohort study," BMC Geriatrics, vol. 16, no. 1, 2016.

[20] H. J. Heppner, T. Bertsch, B. Alber et al., "Procalcitonin: inflammatory biomarker for assessing the severity of communityacquired pneumonia - a clinical observation in geriatric patients," Gerontology, vol. 56, no. 4, pp. 385-389, 2010.

[21] A. Pilotto, S. Dini, J. Daragjati et al., "Combined use of the multidimensional prognostic index (MPI) and procalcitonin serum levels in predicting 1-month mortality risk in older patients hospitalized with community-acquired pneumonia (CAP): a prospective study," Aging Clinical and Experimental Research, vol. 30, no. 2, pp. 193-197, 2018.

[22] A. D. Romano, A. Lo Buglio, F. Bellanti, R. Villani, G. Serviddio, and G. Vendemiale, "Diagnostic reliability of the procalcitonin serum marker in septic frail patient," Aging Clinical and Experimental Research, vol. 31, no. 5, pp. 727732, 2019.

[23] T. Meschi, S. Rossi, A. Volpi et al., "Reorganization of a large academic hospital to face COVID-19 outbreak: the model of Parma, Emilia-Romagna region, Italy," European Journal of Clinical Investigation, vol. 50, no. 6, article e13250, 2020.

[24] I. Arevalo-Rodriguez, D. Buitrago-Garcia, D. SimancasRacines et al., "False-negative results of initial RT-PCR assays for COVID-19: a systematic review," PLoS One, vol. 15, no. 12, article e0242958, 2020.

[25] S. Woloshin, N. Patel, and A. S. Kesselheim, "False negative tests for SARS-CoV-2 infection - challenges and implications," New England Journal of Medicine, vol. 383, no. 6, p. e38, 2020.

[26] A. Nouvenne, M. D. Zani, G. Milanese et al., "Lung ultrasound in COVID-19 pneumonia: correlations with chest CT on hospital admission," Respiration, vol. 99, no. 7, pp. 617-624, 2020.

[27] P. Schuetz, W. Albrich, M. Christ-Crain, J. Chastre, and B. Mueller, "Procalcitonin for guidance of antibiotic therapy," Expert Review of Antinfective Therapy, vol. 8, no. 5, pp. 575587, 2010.

[28] M. Francone, F. Iafrate, G. M. Masci et al., "Chest CT score in COVID-19 patients: correlation with disease severity and short-term prognosis," European Radiology, vol. 30, no. 12, pp. 6808-6817, 2020.

[29] F. Baicry, P. le Borgne, T. Fabacher et al., "Patients with initial negative RT-PCR and typical imaging of COVID-19: clinical implications," Journal of Clinical Medicine, vol. 9, no. 9, article 3014, 2020.

[30] I. Porfyridis, G. Georgiadis, P. Vogazianos, G. Mitis, and A. Georgiou, "C-reactive protein, procalcitonin, clinical 
pulmonary infection score, and pneumonia severity scores in nursing home acquired pneumonia," Respiratory Care, vol. 59, no. 4, pp. 574-581, 2014.

[31] T. Higashikawa, M. Okuro, K. Ishigami et al., "Procalcitonin and albumin as prognostic biomarkers in elderly patients with a risk of bacterial infection," International Journal of Medical Research, vol. 46, no. 7, pp. 2606-2614, 2018.

[32] V. Prendki, A. Malézieux-Picard, L. Azurmendi et al., "Accuracy of C-reactive protein, procalcitonin, serum amyloid A and neopterin for low-dose CT-scan confirmed pneumonia in elderly patients: a prospective cohort study," PLoS One, vol. 15, no. 9, article e0239606, 2020.

[33] C. Villain, C. Chenevier-Gobeaux, J. Cohen-Bittan et al., "Procalcitonin and C-reactive protein for bacterial infection diagnosis in elderly patients after traumatic orthopedic surgery," Journals of Gerontology Series A Biological Sciences Medical Sciences, vol. 75, no. 10, pp. 2008-2014, 2020.

[34] F. Stucker, F. Herrmann, J. D. Graf, J. P. Michel, K. H. Krause, and G. Gavazzi, "Procalcitonin and infection in elderly patients," Journal of the American Geriatrics Society, vol. 53, no. 8, pp. 1392-1395, 2005.

[35] A. Ticinesi, F. Lauretani, A. Nouvenne et al., "C-reactive protein (CRP) measurement in geriatric patients hospitalized for acute infection," European Journal of Internal Medicine, vol. 37, pp. 7-12, 2017.

[36] A. Nouvenne, A. Ticinesi, F. Lauretani et al., "The prognostic value of high-sensitivity C-reactive protein and prealbumin for short-term mortality in acutely hospitalized multimorbid elderly patients: a prospective cohort study," The Journal of Nutrition, Health and Aging, vol. 20, no. 4, pp. 462-468, 2016.

[37] L. D. Chen, Z. Y. Zhang, X. J. Wei et al., "Association between cytokine profiles and lung injury in COVID-19 pneumonia," Respiratory Research, vol. 21, no. 1, p. 201, 2020.

[38] D. Marcos-Pérez, M. Sánchez-Flores, S. Proietti et al., “Association of inflammatory mediators with frailty status in older adults: results from a systematic review and meta-analysis," Geroscience, vol. 42, no. 6, pp. 1451-1473, 2020.

[39] L. Ferrucci and E. Fabbri, "Inflammageing: chronic inflammation in ageing, cardiovascular disease, and frailty," Nature Reviews Cardiology, vol. 15, no. 9, pp. 505-522, 2018.

[40] A. Marengoni, A. Zucchelli, D. L. Vetrano et al., "Beyond chronological age: frailty and multimorbidity predict in-hospital mortality in patients with coronavirus disease 2019," The Journals of Gerontology Series A Biological Sciences Medical Sciences, vol. 76, no. 3, pp. e38-e45, 2021.

[41] L. Zerah, É. Baudouin, M. Pépin et al., "Clinical characteristics and outcomes of 821 older patients with SARS-CoV-2 infection admitted to acute care geriatric wards," The Journals of Gerontology Series A Biological Sciences Medical Sciences, vol. 76, no. 3, pp. e4-e12, 2021.

[42] J. P. Lim, K. Y. H. Low, N. J. J. Lin et al., "Predictors for development of critical illness amongst older adults with COVID19: beyond age to age-associated factors," Archives of Gerontology and Geriatrics, vol. 94, article 104331, 2021.

[43] A. Medetalibeyoglu, N. Senkal, M. Kose et al., "Older adults hospitalized with COVID-19: clinical characteristics and early outcomes from a single center in Istanbul, Turkey," The Journal of Nutrition, Health and Aging, vol. 24, no. 9, pp. 928-937, 2020.

[44] M. Falcone, G. Tiseo, C. Giordano et al., "Predictors of hospital-acquired bacterial and fungal superinfections in
COVID-19: a prospective observational study," Journal of Antimicrobial Chemotherapy, vol. 76, no. 4, pp. 1078-1084, 2021.

[45] C. Garcia-Vidal, G. Sanjuan, E. Moreno-García et al., "Incidence of co-infections and superinfections in hospitalized patients with COVID-19: a retrospective cohort study," Clinical Microbiology and Infection, vol. 27, no. 1, pp. 83-88, 2021.

[46] T. Chen, Z. Dai, P. Mo et al., "Clinical characteristics and outcomes of older patients with coronavirus disease 2019 (COVID-19) in Wuhan, China: a single-centered, retrospective study," The Journals of Gerontology Series A Biological Sciences Medical Sciences, vol. 75, no. 9, pp. 1788-1795, 2020.

[47] E. Pujadas, F. Chaudhry, R. McBride et al., "SARS-CoV-2 viral load predicts COVID-19 mortality," The Lancet Respiratory Medicine, vol. 8, no. 9, p. e70, 2020.

[48] C. Anastassopoulou, Z. Gkizarioti, G. P. Patrinos, and A. Tsakris, "Human genetic factors associated with susceptibility to SARS-CoV-2 infection and COVID-19 disease severity," Human Genomics, vol. 14, no. 1, p. 40, 2020.

[49] P. Zhang, L. Zhu, J. Cai et al., “Association of inpatient use of angiotensin-converting enzyme inhibitors and angiotensin II receptor blockers with mortality among patients with hypertension hospitalized with COVID-19," Circulation Research, vol. 126, no. 12, pp. 1671-1681, 2020.

[50] ITA-COVID-19: RAAS inhibitor group, G. Trifirò, M. Massari et al., "Renin-angiotensin-aldosterone system inhibitors and risk of death in patients hospitalised with COVID-19: a retrospective Italian cohort study of 43,000 patients," Drug Safety, vol. 43, no. 12, pp. 1297-1308, 2020.

[51] A. Medetalibeyoglu, G. Bahat, N. Senkal et al., "Mannose binding lectin gene 2 (rs1800450) missense variant may contribute to development and severity of COVID-19 infection," Infection, Genetics and Evolution, vol. 89, article 104717, 2021.

[52] The GenOMICC Investigators, The ISARIC4C Investigators, The COVID-19 Human Genetics Initiative et al., "Genetic mechanisms of critical illness in COVID-19," Nature, vol. 591, no. 7848, pp. 92-98, 2021. 